\title{
Ranking different cities and villages in province of Isfahan based of analysis of social indicator during the statistic period 1996-2006
}

\author{
Asghar Zarabi ${ }^{\mathbf{a}^{*}}$ and Dariush Ahmadi ${ }^{\mathbf{b}}$
}

${ }^{a}$ Professor of Geography and city planning, university of Isfahan, Isfahan, Iran

${ }^{b} \mathrm{PhD}$ student of Geography and city planning, university of Isfahan, ,Isfahan, Iran

\begin{tabular}{l}
\hline A R T I C L E I N F O \\
\hline Article history: \\
Received April 17, 2012 \\
Accepted 11 June 2012 \\
Available online \\
June 12 2012 \\
\hline Keywords: \\
Leveling \\
Social indicators \\
Factor analysis \\
Towns of Isfahan state \\
\end{tabular}

\section{A B S T R A C T}

\begin{abstract}
One of the primary governmental concerns is to understand the level of economical and social development in different locations of a country. Understanding social and economical characteristics of different cities help provide necessary assistance for underdeveloped areas and promote some value added activities such as tourism in better-developed areas. In this paper, we present an empirical study based on Factor Analysis to rank different towns, villages and cities located in city of Isfahan, Iran in terms of various socio-economical criteria. The study gathers necessary information from 1996 to 2007. The results of our survey indicate that three cities of Feridan, Nayeen and Falavarjan are in the best position in terms of different social and cultural criteria while Lenjan, Barkhar and Mymehand Isfahan are located in the worst positions.
\end{abstract}

(C) 2012 Growing Science Ltd. All rights reserved.

\section{Introduction}

Although talking about culture has a long historical background, the subject of culture development has become a part of country and social development in recent decades. When talking about economic development and politics development, eking should be attending to culture politics (hadadian1996). The indicators of culture development were first mentioned in 1967 in a panel discussion containing experts of 24 of countries in UNESCO until study about culture politics. Since then, there have been different works associated with factors influencing socio-economic development. Gukalova et al. (2009) highlighted the characteristic features of the socio-geographical technique in studying the "quality of life of population". They determined the most important parameters, which are responsible for the quality of life in these countries and presented some experience in evaluating the balanced development of Ukraine and Russia.

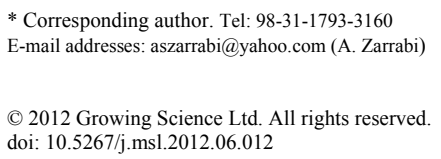


Human migration is one of the conflict constellations in regions influenced by climate change, but can also contribute to climate adaptation. Migrant social networks can help us build social capital to increase the social resilience in the communities of origin and trigger innovations across regions by the transfer of knowledge, technology, remittances and other resources. This also helps absorbs more people as tourist in the regions. Gaughan et al. (2009) presented some models to investigate the impact of tourism forest conversion, and land transformations in the Angkor basin, Cambodia.

Ryashchenko and Gukalova (2010) explained that public health in the system can be a major indicator of the quality of life in countries like Russia and Ukraine. They discussed the methodological issues of using the public health indices as an assessment of the quality of life in regions of Russia and Ukraine. They also investigated the relationship between the notions "public health" and "quality of life" and outlined the techniques of comparative assessment of public health at the level of the countries and their regions. The influence of the public health level on international ratings of Russia and Ukraine was studied in terms of the potential of human development. They also presented the factors and conditions of the spatial differentiation of public health indices in some regions of Russia and Ukraine.

Kancs (2011) explored labor migration in the enlarged EU by adopting the Krugman's framework of the New Economic Geography. They studied determinants of labor migration, such as market potential, wages, cost of living on one hand, and labor migration on the other hand, simultaneously, which helped address important issues facing the traditional reduced form studies. They reported that European integration would trigger labor migration between and within the Member States of the enlarged EU.

$\mathrm{Su}$ et al. (2012) qualitatively investigated urbanization influences at an eco-regional scale by analyzing landscape pattern and ecosystem service value changes in four eco-regions in China. Their results indicated that the four eco-regions exhibited a similar urbanization process of rapid population growth, economic development and urban expansion. They reported that the considerable urban expansion led to a loss of 8.5 billion RMB yuan ecosystem service values per year on average between 1994 and 2003 and found that landscape fragmentation, configuration and diversity, which were induced by urbanization, could substantially impair the provisions of ecosystem services. Their results emphasized the importance of joint application of landscape metric analysis and ecosystem service values assessment in landscape planning.

Dennis Wei and Liefner (2012) explained the drastic rise of China in foreign investment, export, and ICT production. They explained that the research on China was embedded in China's reform process, as well as theoretical development in economic geography through a comprehensive review of the literature on globalization, industrial restructuring and regional development. Hewitt and Escobar (2011) explained that urban development was an intensive and poorly controlled issue in Spain and they warned serious concerns for sustainability in the territory. They suggested that to move towards a more sustainable configuration, it is necessary to acquire the implication of all stakeholders in the Madrid region. They presented a framework for implementation of sustainable development initiatives through sustainability action groups, in which integrated land use techniques and participatory planning activities were used to test and develop new policy initiatives. Transportation plays an important role on urban development and air transportation is considered as one of the most important items in some areas. Fenley et al. (2007) investigated whether air transport must be considered seriously as a major transport option for the sustainable development of Amazonas.

Scheffran et al. (2012) investigated possible opportunities, innovative methods and institutional techniques for migration as a contribution to climate adaptation. They used the Western Sahel as a case study region, with a focus on Mali, Mauritania and Senegal, using quantitative and qualitative analysis of remittances at the national level, and a micro-level analysis on the role of migrant networks in these countries in specific co-development projects in water, food and energy. 
In this paper, we present an empirical study to rank different regions of city of Esfahan in terms of their socio-economical features. The organization of this paper first presents details of the survey in section 2, section 3 explains details of our findings and concluding remarks are given at the end to summarize the contribution of the paper.

\section{The proposed study}

Social development is one of the most important components of development of any country. Social development has different meaning from various point of view such as passing traditional society to modern or industry by division of affaires or social invest, human identity rational, communicative, trust, etc. In Iran this concept is more in accordance with identity and trust. Social development in 1995 was introduced as defeating with poverty. The indictors of development include reaches to educational services, percent of educated population, life length of time the ratio of death, appropriate nourish sanitation level and controlling of diseases and etc shelter suitable, equal between men and women, etc.

Human development is one of the most important issues and is confronting with poverty and injustice that should be provided by social policies. Social development with division of social living in to 4 parts of political, economical, culture and social has become more important. The focus of social development is a society that according to it all the political, economical, culture and social dimensions has been taken to account either micro or macro level. Development is a very complicated process where society transfers from a historical era to another new one.

The province of Isfahan has always been one of the pioneers in development of Iran. Regional analysis specially, in balanced development and factor of different regions in territory of Isfahan province indicates the imbalance in development and social justice. This province maintains the following characteristics.

\subsection{Social -cultural development and its indicators}

This research is about analysis of changes of one of the most important dimensions of development, which is social development or social-cultural development. In fact because of the very interference of this development we use the combination word social-culture word. Social-culture development means the change in following aspects: 1-populational issues, 2-educational issues, 3-occupational issues, 4- matrimonial issues, 5-treating -sanitation issues, 6-book and book reading, and 7-press and media.

\subsection{Methodology}

The methodology is quantitative -analyzing the statistic group of research are the cities at Isfahan. The needing data are accumulated (gathered) from general counting of people and domicile of 1996 and 2006 and by using Factor analysis (FA) we analyze social cultural indicators in the cities located in province of Isfahan. The primary objectives are to analyze the social, cultural indicators in the cities located in the province, to reduce the number of items using FA and finally to rank all cities based on the criteria. FA is considered as a statistical method used to explain variability among observed, correlated variables in terms of a potentially lower number of unobserved components called factors. In other words, it is possible, for instance, that variations in five or six observed variables mainly reflect the variations in fewer such unobserved variables. FA looks for such joint variations in response to unobserved latent ones. The observed variables are formulated as linear combinations of the potential components, plus "error" terms. The data gained about the interdependencies among observed variables are used later to reduce the set of variables in a dataset (Fabrigar et al., 1999). 


\subsection{Characteristics of the province of Isfahan}

Isfahan province with area of $107090 \mathrm{~km}^{2}$ and more than 4559256 population is located between 30 and 43 min based on last statistical information in 1386 this province had 22 cities , 45 parts , 46 towns, 124 villages and its centre was Isfahan. Fig. 1 shows the location of this province in Iran.

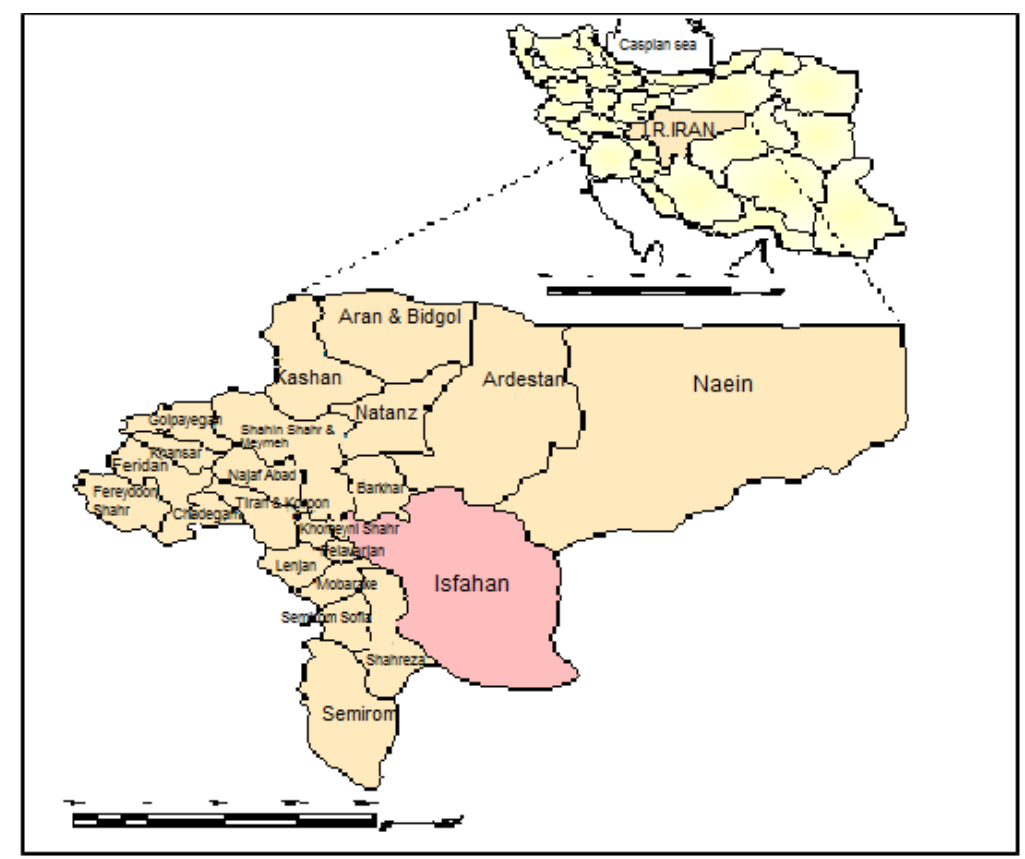

Fig. 1. The province of Isfahan

Table 1 shows the number of towns, parts, city and villages at Isfahan state based on country division.

Table 1

Characteristics of the city of Isfahan

\begin{tabular}{lcccc}
\hline year & village & city & part & town \\
\hline 2001 & 121 & 83 & 43 & 19 \\
2004 & 122 & 91 & 43 & 21 \\
2007 & 124 & 96 & 45 & 22 \\
\hline
\end{tabular}

Data matrix for technique of FA should have meaningful information and we use KMO Bartlett's test to verify whether the data represent meaningful numbers. Table 2 shows details of our findings.

Table 2

KMO and Bartlett's test for indicator culture and social development in Isfahan

\begin{tabular}{lcc}
\hline Kaiser-Meyer-Olkin Measure of Sampling Adequacy. & 0.734 \\
Bartlett's Test of Sphericity & Approx. Chi-Square & 1064 \\
\hline Df & & 351 \\
Sig. & 0 \\
\hline
\end{tabular}

As we can observe from the results of Table 2, Chi-Square represents a meaningful value, which validates the results of our FA analysis. Table 3 shows details of the criteria used for analyzing the cities and towns including cinema, salon, etc. and the associated correlation numbers assigned to them. 
Table 3

Coloration matrix socio-culture variance in cities located in province of Isfahan

\begin{tabular}{|c|c|c|c|c|c|c|c|c|c|c|c|c|c|c|c|}
\hline & cinema & salon & present & print & library & canon & university & expo & bulletin & Imamzadeh & mosque & hosinee & least & bequest & domicile \\
\hline cinema & 1.00 & 0.98 & 0.99 & 0.99 & 0.99 & 0.98 & 0.984 & 0.30 & 0.98 & 0.75 & 0.91 & 0.63 & 0.86 & 0.58 & 0.99 \\
\hline salon & 0.98 & 1.00 & 0.98 & 0.98 & 0.98 & 0.97 & 0.975 & 0.27 & 0.98 & 0.75 & 0.90 & 0.61 & 0.86 & 0.56 & 0.97 \\
\hline present & 0.99 & 0.98 & 1.00 & 0.998 & 0.997 & 0.998 & 0.999 & 0.27 & 0.999 & 0.72 & 0.91 & 0.58 & 0.88 & 0.54 & 0.999 \\
\hline print & 0.99 & 0.98 & 0.998 & 1.00 & 0.998 & 0.997 & 0.998 & 0.26 & 0.998 & 0.72 & 0.91 & 0.59 & 0.87 & 0.55 & 0.997 \\
\hline library & 0.99 & 0.98 & 0.997 & 0.998 & 1.00 & 0.996 & 0.996 & 0.28 & 0.996 & 0.73 & & 0.59 & 0.87 & 0.55 & 0.996 \\
\hline canon & 0.98 & 0.97 & 0.998 & 0.997 & 0.996 & 1.00 & 0.998 & 0.28 & 0.998 & 0.71 & 0.91 & 0.57 & 0.86 & 0.54 & 0.997 \\
\hline university & 0.98 & 0.98 & 0.999 & 0.998 & 0.996 & 0.998 & 1.00 & 0.27 & 0.876 & 0.70 & 0.90 & 0.56 & 0.87 & 0.53 & 0.998 \\
\hline expo & 0.30 & 0.27 & 0.270 & 0.257 & 0.282 & 0.279 & 0.272 & 1.00 & 0.27 & 0.10 & 0.37 & 0.56 & 0.16 & 0.13 & 0.26 \\
\hline magazine & 0.98 & 0.98 & 0.999 & 0.998 & 0.996 & 0.998 & 0.987 & 0.27 & 1.00 & 0.70 & 0.90 & 0.56 & 0.87 & 0.53 & 0.998 \\
\hline Imamzade & 0.75 & 0.75 & 0.725 & 0.722 & 0.728 & 0.714 & 0.701 & 0.10 & 0.70 & 1.00 & 0.72 & 0.91 & 0.69 & 0.85 & 0.74 \\
\hline masque & 0.91 & 0.90 & 0.907 & 0.910 & 0.917 & 0.914 & 0.903 & 0.37 & 0.90 & 0.72 & 1.00 & 0.63 & 0.76 & 0.69 & 0.91 \\
\hline hosinee & 0.63 & 0.61 & 0.580 & 0.588 & 0.589 & 0.568 & 0.558 & 0.05 & 0.56 & 0.91 & 0.63 & 1.00 & 0.55 & 0.90 & 0.60 \\
\hline least & 0.86 & 0.86 & 0.877 & 0.870 & 0.873 & 0.860 & 0.867 & 0.16 & 0.87 & 0.69 & 0.76 & 0.55 & 1.00 & 0.46 & 0.88 \\
\hline bequest & 0.58 & 0.56 & 0.544 & 0.553 & 0.553 & 0.543 & 0.529 & 0.13 & 0.53 & 0.85 & 0.69 & 0.90 & 0.46 & 1.00 & 0.57 \\
\hline domicile & 0.99 & 0.97 & 0.999 & 0.997 & 0.996 & 0.997 & 0.998 & 0.26 & 0.88 & 0.74 & 0.91 & 0.60 & 0.88 & 0.57 & 1.00 \\
\hline
\end{tabular}

We have also use principle component analysis (PCA) to find important factors influencing development of cities. Our PCA implementation yields a total standard deviation of 7.485 where the first factor with 3.5 maintains the most influencing effect. Fig. 2 shows details of our findings regarding PCA analysis.

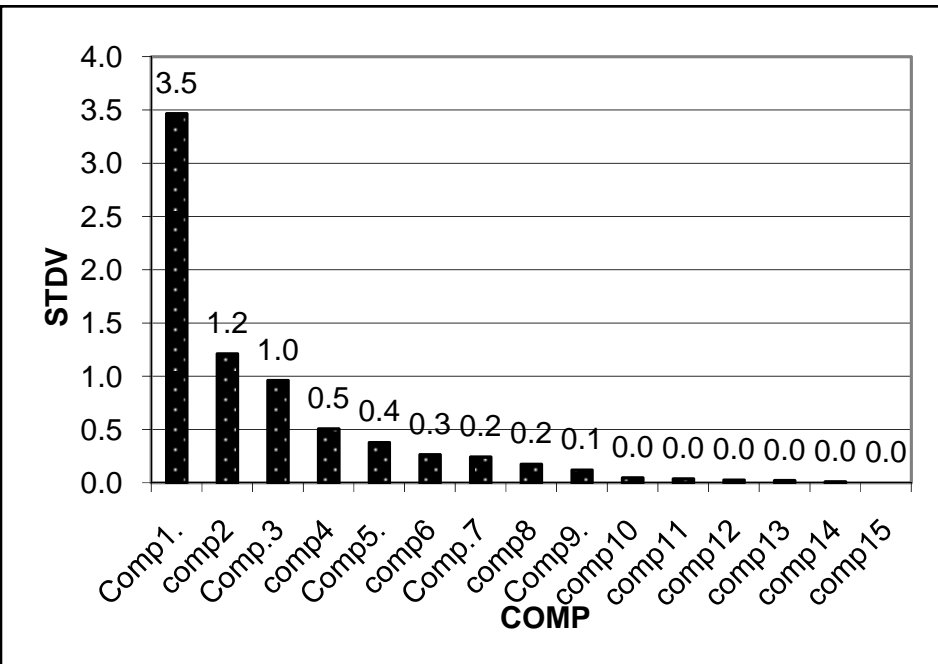

Fig. 2. Standard deviation of different components

Analysis of variance (ANOVA) test was another technique to examine different impacts of various factors. Fig. 3 shows details of our finding where the first factor represents $80.1 \%$ of variance of factors.

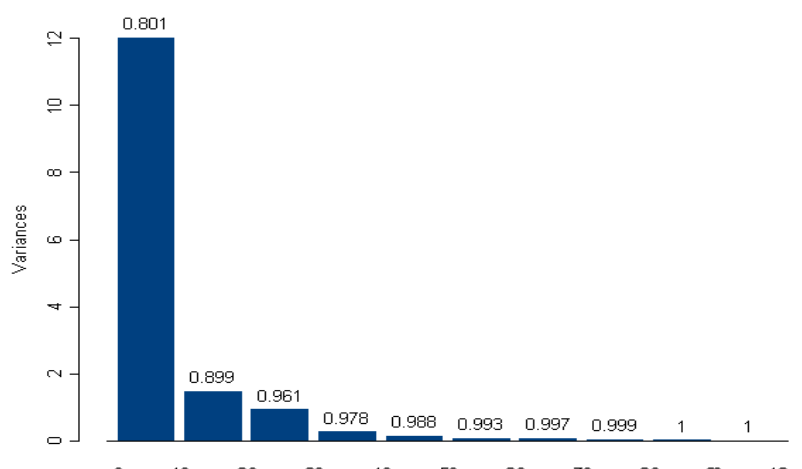

Fig. 3. The results of ANOVA test 
In summary, the results of our analysis indicates that cinema, number of saloons, number of theatre and musical places, painting, public library, brain nourish for infant and juveniles are the first six important factors, respectively. In addition, the existence of university, items of arts and culture for export, local press, Islamic places blessedness, mosque, hosineey (a kind of religious place), religious places, number pious foundation and residence installation come in other orders, respectively. Fig. 4 shows details of our classifications.

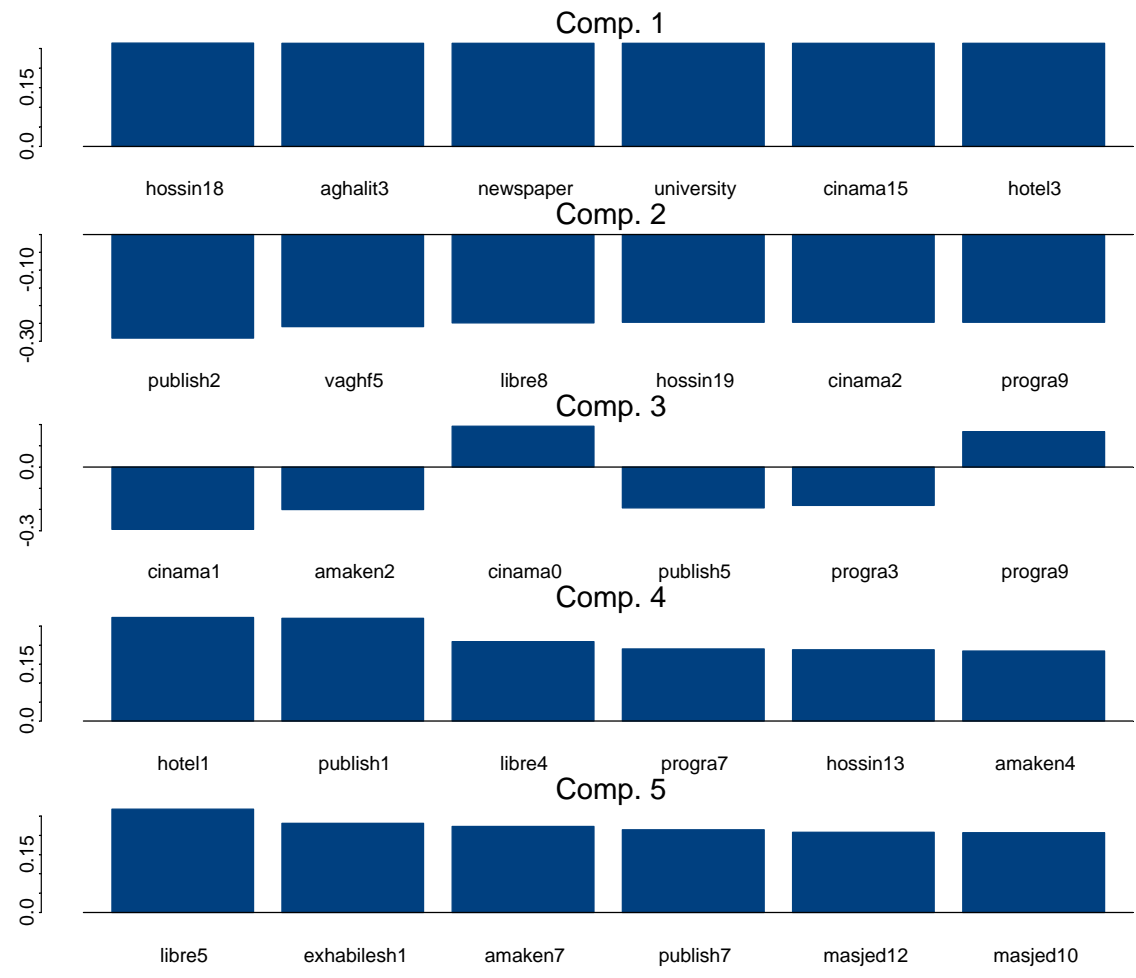

Fig. 4. Classification of different items

\section{The results}

In order to find out the relative importance of each criteria, we should inspect separately indicators of each part on illiteracy rate, which is an important indicator in social development. There are not much differences between illiteracy rates in different cities due to expending education centres and learning in all of the country, nevertheless, the largest literate rate change is $6.45 \%$ for Semirom and the least is $1.55 \%$ for Falavarjan and the ranking of the cities are summarized in Table 4.

\section{Table 4}

The ranking for different cities in terms of the growth level in literacy (1996-2006)

\begin{tabular}{lcclcc}
\hline Township & Amount grow literate rate & Rank & Township & Amount grow literate rate & Rank \\
\hline Semirom & 6.45 & 1 & Barkhar and Meymeh & 3,28 & 12 \\
Naein & 6.09 & 2 & Lanjan & 3,27 & 3.24 \\
Fereydoon Shahr & 5.76 & 3 & Najaf Abad & 3.03 & 13 \\
Chadgan & 5.52 & 4 & Khomeyni Shahr & 2.95 & 15 \\
Golpayegan & 5.33 & 5 & Semirom Sofla & 2.69 & 16 \\
Tiran and Koroon & 4.39 & 6 & Isfahan & 2.66 & 17 \\
Natanz & 4.28 & 7 & Aran \& Bidgol & 2.64 & 18 \\
Ardestan & 3.81 & 8 & Khansar & 2.55 & 19 \\
Kashan & 3,72 & 9 & Mobarakeh & 1.55 & 20 \\
Shahreza & 3.69 & 10 & Felavarjan & & 21 \\
Feridan & 3.37 & 11 & & & \\
\hline
\end{tabular}


Increasing in the rate of literacy in the level of cities of province, on one hand is because of old illiterates people and on the other hand is because of expansion of educational services. There are some reasons to encourage people to learn more. Among these, we can refer to percentage indicator of accessibility to newspaper in different cities. The best one is Natanz with $235.94 \%$ and the least one is Golpayegan \& Feridan with $-100 \%$ (See Table 5).

\section{Table 5}

Cities sate Isfahan ranking about percent accessibility to bulletin (1996-2006)

\begin{tabular}{|c|c|c|c|c|c|}
\hline Township & Amount grow literate rate & Rank & Township & Amount grow literate rate & Rank \\
\hline Natanz & 235.94 & 1 & Semirom Sofla & -6.72 & 11 \\
\hline Najaf Abad & 231,29 & 2 & Semirom & -18.52 & 12 \\
\hline Shahreza & 213.39 & 3 & khansar & -45.29 & 13 \\
\hline Kashan & 160.96 & 4 & Barkhar \& Meymeh & -50.78 & 14 \\
\hline Aran \& Bidgol & 104.95 & 5 & Isfahan & -65.04 & 15 \\
\hline Flavarjan & 42.48 & 6 & Lanjan & -67.04 & 16 \\
\hline Naein & 25.58 & 7 & Mobarake & -78.04 & 17 \\
\hline Ardestan & 23.91 & 8 & Feridan & -100 & 18 \\
\hline Khomeyni Shahr & 13.33 & 9 & Golpayegan & -100 & 19 \\
\hline Fereydoon Shahr & 3.39 & 10 & & & \\
\hline
\end{tabular}

Prediction about status of mass media is complex because against the number of statistic we face to culture case, for example if public library, book, cinema, and etc. would increase we would not be able to say the culture is improved. Finally after using the factor analysis we calculate the statue of cultural and social development in cities and the result is that the worst condition is in Isfahan and the best condition is in Feridan and other cities are summarized in Table 6 as follows.

Table 6

Cities end ranking based to total indicator (1996-2006)

\begin{tabular}{|c|c|c|c|c|c|c|c|c|c|}
\hline township & rank & township & rank & township & rank & township & rank & township & rank \\
\hline Feridan & 1 & Najaf Abad & 5 & Khomeyni Shahr & 9 & Ardestan & 13 & Isfahan & 17 \\
\hline Naein & 2 & Mobarakeh & 6 & Natanz & 10 & Khansar & 14 & & \\
\hline Felavarjan & 3 & Fereydoon Shahr & 7 & Golpayegan & 11 & Lanjan & 15 & & \\
\hline Kashan & 4 & Shahreza & 8 & Semirom & 12 & Brkhar \& Meymeh & 16 & & \\
\hline
\end{tabular}

Note that the ranking does not mean that Faridan is the best facilities and Isfahan is the worst one because these variances have improved in 1996-2006. In fact, when we calculate and compare indicators of 1996-2006 we receive the information of Table 7 as follos.

Table 7

Cites end ranking based to social-culture indicator (1996-2006)

\begin{tabular}{|c|c|c|c|c|c|c|c|c|c|}
\hline township & rank & Township & rank & township & rank & township & $\begin{array}{c}\text { ran } \\
\mathrm{k}\end{array}$ & township & $\begin{array}{c}\text { ran } \\
\mathrm{k}\end{array}$ \\
\hline Kashan & 1 & Shahreza & 5 & Naein & 9 & Barkhar and Meymeh & 13 & Flavarjan & 17 \\
\hline Isfahan & 2 & Ardestan & 6 & Lenjan & 10 & Khomeyni Shahr & 14 & & \\
\hline Khansar & 3 & Golpayegan & 7 & Semirom & 11 & Feridan & 15 & & \\
\hline Najaf Abad & 4 & Natanz & 8 & Mobarakeh & 12 & Freydoon Shahr & 16 & & \\
\hline
\end{tabular}

As we can observe from the results of Table 7, Kashan maintains the highest ranking followed by Isfahan, Khansar and Najafabad while Flavarjan comes at the end in terms of ranking. 


\section{Conclusion}

In this paper, we have presented an empirical study to measure the relevant importance of various cities in terms of different criteria including population growth rate, literate rate, newspaper access, public library, cinema, number of salon, etc.. The proposed study used Factor Analysis to find important components influencing development of different villages and cities located in province of Isfahan, Iran. The study considered 15 criteria and applied for 17 cities in this province. The results of our study indicate that Kashan was in the best position and Falavarjan was in the worst position.

Of course, we should pay attention to population variances specially population emigration, which means that some of cities have the high facility but due to the population growth and emigration they have found the best conditions.

\section{Acknowledgment}

The authors would like to thank the anonymous referees for their constructive comments on earlier version of this paper.

\section{References}

Dennis Wei, Y.H., \& Liefner, I. (2012). Globalization, industrial restructuring, and regional development in China. Applied Geography, 32(1), 102-105.

Fabrigar, L. R., Wegener, D. T., MacCallum, R. C., \& Strahan, E. J. (1999). Evaluating the use of exploratory factor analysis in psychological research. Psychological Methods, 4(3), 272-299.

Fenley, C.A., Machado, W.V., \& Fernandes, E. (2007). Air transport and sustainability: Lessons from Amazonas. Applied Geography, 27(2), 63-77.

Gaughan, A.E., Binford, M.W., \& Southworth, J. (2009). Tourism, forest conversion, and land transformations in the Angkor basin, Cambodia. Applied Geography, 29(2), 212-223

Gukalova, I.V., Lisovsky, S.A., Maruniak, E.A., Misevich, K.N., Rudenko, L.G. \& Ryashchenko, S.V. (2009). The quality of life in Ukraine and in Russia as a factor of socio-economic development. Geography and Natural Resources, 30(3), 300-305.

Kancs, D. (2011). The economic geography of labour migration: Competition, competitiveness and development. Applied Geography, 31(1), 191-200.

Hewitt, R., \& Escobar, F. (2011). The territorial dynamics of fast-growing regions: Unsustainable land use change and future policy challenges in Madrid, Spain. Applied Geography, 31(2), 650667.

Ryashchenko, S.V., \& Gukalova, I.V. (2010). Public health in the system of regional indicators of the quality of life in Russia and Ukraine. Geography and Natural Resources, 31(1), 11-17.

Scheffran, J., \& Marmer, E., \& Sow, P. (2012). Migration as a contribution to resilience and innovation in climate adaptation: Social networks and co-development in Northwest Africa. Applied Geography, 33, 119-127.

Su, S., Xiao, R., Jiang, Z., \& Zhang, Y. (2012). Characterizing landscape pattern and ecosystem service value changes for urbanization impacts at an eco-regional scale. Applied Geography, 34, 295-305. 